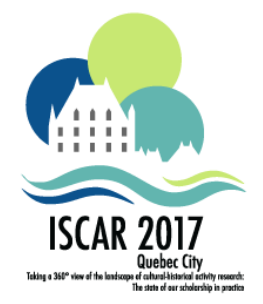

\title{
Play and Toy in the frame of Cultural-Historical Psychology
}

\author{
Elena O. Smirnova \\ Moscow State University of Psychology and Education \\ Moscow, Russia
}

SMIRNEO@MAIL.RU

\begin{abstract}
The intention of this paper is to show the specific of L. S. Vygotsky's approach to child play and toy as the tool of play. Vygotsky paid special attention to pretend play the essence of which consists in a divergence of the imagined and real situation. Such play promotes the development imagination, thinking, self-control, voluntary behavior, self-awareness, social interrelationship, emotional intelligence. The main tools of a children play are toys. Functions and characteristics of toys are presented. It is indicated that the good toys should be open for various actions and the ideas of the child. However the majority of modern toys are equipped with technical devices which don't allow the child to show his/her own activity. Playing with such toys comes down to a putting buttons that unlike a pretend play doesn't develop the abilities in the child. Tech toys, and electronic games present a new developmental situation and it is necessary to study the impact this kind of activities have on the development of young children. In the last part of article criteria of psychological examination of toys are presented.
\end{abstract}

Keywords : Play; Pretend play; Imaginary situation; Traditional toys; Tech toys; Child development; Child's activity; Psychological examination of toys. 


\section{Play as leading activity in preschool age}

L. S. Vygotsky is the founder of theory of play as leading activity in preschool age. The cultural-historical approach to children's play is part of Vygotsky's general theory of the origin and development of the higher mental functions. It should be noted that he studied a special kind of play - pretend one. Vygotsky advanced the view that pretend symbolic play is the origin of consciousness development in preschool age. It should be pointed out that Vygotsky differentiated between the predominant and leading forms of activity: the predominant activity is the one that takes up most of the time, while the leading activity is the one which determines mental and personal development. Play may not be the predominant form of children's activity; however, it is during play that the main new mental formations emerge during the period 3 to 7 years, and that is why it is the leading activity (Vygotsky, 2004, 2005).

According his theory the main sense of child play is the imaginary situations. Imaginary situation is the main specific property of pretend play distinguishing it from any other activities. Imaginary situation exists in the child's practical play actions (individual or joint) rather than in his/her imagination. It is a simultaneous holding to both real and illusory situation. The child's actions are determinated by his/her ideas, rather than real visible objects. Due to these characteristics of play, it serves as a base for the effectively develop creative imagination, image thinking, self-awareness, etc.

Vygotsky (following K. Lewin) emphasized that until the age of three the child is totally dependent on the situation. This dependence on the perceived field reveals itself both in the child's actions and utterances. Vygotsky believed that this dependence on the situation resulted from the unity of the affect and perception (Vygotsky, 2005). Perception in early age is the initial point of the affective-motor reaction. It is interesting that Vygotsky, unlike Piaget, did not analyze the sensory-motor, but the affective-motor reaction, in which perception and action relate through affect. Since a situation is always given in perception and perception is not separated from affect and, consequently, from movement, the child is dependent on the situation in which he/she finds him/herself.

After three years of age, in developed forms of play activity, the child demonstrates a totally different and even contrary type of behavior. The child does not act in a visual situation he perceives but in an imaginary situation in his mind, ascribing names and functions to objects, that are totally uncharacteristic of them. According to Vygotsky, the creation of an imaginary, make-belief situation is the key element of play, which sets it apart from other kinds of activity. He defined the main characteristic of child play as the divergence between the real and imaginary situations: "A child in a play starts acting "not from an object but from a thought", not in a real but in an illusory, imaginary situation" (Vygotsky, 2004, p. 210). Due to these characteristics of play, it serves as a base for the forming and effectively developing the major new characteristics of this age period facilitating the buildup of consciousness and the internal plane of action as specifically human features (Elkonin, 1978). 
But the questions are: How certain objects in play are replaced by others (i.e., to study the special features of play symbolism), and, secondly, What enables the child to use objects "symbolically" in make-believe situation. So, we should to consider the genesis of the symbolic function.

It is well known that J. Piaget was the first to pose the problem of symbolism in play. He linked it to the development of representative intelligence, believing that the main precondition for this was the emergence of a symbol, i.e., the relation between the signifier and the signified. However, Vygotsky rejected such approach which, in his view, could result in an intellectualistic understanding of play. He wrote, "If play is understood as symbolism, it is thereby turned into a system of some signs generalizing objective reality which no longer has anything specific for play" (Vygotsky, 2004, p. 215). Play is not cognitive or intellectual activity; it is the child's practical activity and it is always connected with his real (not symbolic) affects and emotions. The transition from natural to mediated action is made when both the intellectual and the affective are at work.

The basic characteristic of pretend play is object substitution. Considerable number of objects can be used to replace others. However, there are certain limits to the use of objects in play that at first glance appear to be the result of the outward similarities between the signifier and the signified. What determines these limits? Vygotsky's experiments provide a preliminary answer to this question. During an experiment, child were requested to participate in a tongue-in-cheek play of supplying new names to familiar objects. For example, a book was used to designate a house, keys - children, a knife - a doctor, a pencil - a nurse, etc. A simple story with these objects would be shown to three-to-five-year-old children, for example, a doctor came to a house, where a nurse opened the door for him; he examined the children and gave them medicine, etc. It turned out children had no difficulty in following the plot and that the similarity of objects did not play any important role in reading this "object notation". The main condition was that objects allowed certain actions to be performed with them. Children rejected objects only when they could not be used to make the required gesture or action. This study raised the problem of the function of activity in establishing the relationship between word, object and action(Vygotsky, 2005). It should be emphasized that imaginary situation in play exists in the child's practical actions (individual or joint) rather than in his/her mind. It is important that at first kids act with an objects during playing in a substituting manner and only later give it a new play name. In early stages of the development of play (as distinct from its subsequent phases), the child is unable to perform an appropriate action with an object, before he/she gives a new name to it.

\section{Functions of toy in child's play}

The postulate that signs as cultural phenomena are media or tools of man's internal psychological activity is pivotal to Vygotsky's cultural-historical concept (Vygotsky, 1982). By analogy with work tools signs are psychological tools used by person to build own inner world and to organize his/her own behavior. According to Vygotsky, the specificity 
of human behavior is that it involves sign mediation. The main function of signal tools is to objectify one's own behavior by transforming it into a special object, separate from man. This behavior no longer 'coincides' with the subject of activity and thus enables its cognizance and control (self-regulation).

Speech is the most universal system of signal instrumental media. That is why, according to Vygotsky, the development of speech mediation is central to the child's mental development. Speech is of universal importance in liberating man from the pressure of the existing situation and making him behave consciously (Vygotsky, 1984).

However, speech is far from the only means of taking cognizance and therefore control of one's own behavior. Different models, rules or ways of acting can also serve as such media. Children begin to act consciously and deliberately when their actions are mediated by an idea of 'how they are to act'. Such mode of behavior can be set in the form of a general rule or play role or else the behavior of a concrete person. A role as a mode of behavior includes instrumental function. It is important, because it becomes a model, with which the child can compare his behavior. By comparing it with the model the child becomes cognizant of his own behavior and takes a certain attitude to it.

It can be surmised that toy has a function of psychological tool (Smirnova, 2011).

Toy is the most traditional cultural tool created by adults to develop children. Toys promote children's learning about the world and themselves, realizing their creativity, expressing feelings and communicating. Nowadays toys of a new generation differ greatly from the traditional ones become very popular. That's why it is very important to understand their impact on the children's development and to evaluate their developmental potential.

The theoretical basis of the toys' evaluation is a cultural-historical and activity approach to mental development. According to this approach, the essence of ontogenetic development is the assimilation of cultural and historical experience in the course of child-adult joint activity (Vygotsky, 1984). Mastering this experience takes place in the child's culturally adjusted activity that ensures the transfer from inter- to intrapsychical form, encouraging the appearance of new individual psychic and personal features. Each type of child's activity is realized with the help of certain means conducive to mastering various aspects of cultural experience, at first in joint activity with adults, and later in the independent activity of a child. Toys are the only accessible cultural means that can be used for independent activities at an early age, creating the zone of proximal development.

Independent activity of a child with a toy is called as "play". Talking about toys, we have in mind two meanings of the term "play". In the wide sense, play is any child's activity with toys or play material. In the narrow sense, play means creation of a conditional imaginary situation with toys or without them.

Play activity of a child may be considered as a special form of transfer and mastering of cultural experiences that reflects the peculiarity of children's life in society. This means 
toy is a specific psychological mean that objectify the tasks of psychological and personal development at all age periods. The main requirement to a toy is an ability to expand those types of activities that contribute the most efficient stimulation of the leading activity.

The tasks of mental and personal development and the means provided for this purpose are different and have qualitative specifics for each age period.

At the same time, the main function of toys for all stages of child development is to encourage age-appropriate child's activities.

Toys are the main attributes of child play and for creation imaginary situations. Two crucial processes centering on toy take place simultaneously. On the one hand, the child expresses him/herself - his (her) knowledge, emotions, moods and events of life. By observing how children play one can understand their inner world and what is bothering them.

On the other hand, when playing, the child masters the world of human relations and ideas, in which he/she lives. Toys always reflect the world outlook of those adults, their ideology, tastes, fashion, etc. They are the special psychological tools for a child's education. A 'dialogue' with a toy (especially with a doll) is an important phase of the development of inner dialogue, which will subsequently transform into inner speech, a chief means of human thought and consciousness.

This implies requirements on the quality of the toys. It should adequately reflect reality (both material and idea), and be open for inner world of child.

A good toy ought primarily to be open to the different actions and emotions of the child. Toys should make it possible for children to impart their own activity - their voices and movements - to it. To remain being media, toys should not impose themselves nor suggest concrete actions. Only this way can toys become psychological media rather than merely an object of manipulations.

Role attributes as specific things should likewise not monopolize the child's attention. They are needed to enable children to feel they are somebody else and to retain that feeling rather than to impress or surprise. Their function is to become conventional yet commonly recognized role signs.

For the child to get the meaning of relations between people, play activity should be conventional and open for conditional meanings. The more detailed is an action in practice, the more compressed and subconscious is the role relations plan. In child play the conventional or detailed nature of a practical action largely depends on whether the toy is simple or complex, realistic or not. For this reason, objects used in role-playing should not be actual copies of real things. They do not monopolize the child's attention but allow to use them instead of the conventional designation of things. The fact that play actions are generalized and contracted (i.e., made conventional) shows that the inner plan, that 
is, relations between people and their emotional experience, has become important to the child.

Unfortunately, the majority modern tech toys are closed for kid's mental and motor activity.

Toys are becoming self-sufficient, automatic things. Whenever toys have intricate technological equipment and impose certain modes of acting, they inhibit not only imagination in children but also their inner psychological life. Such toys dictate children what to do with it.

Dolls can talk by themselvs, sing, dance and so on. Instead of stimulating children to play, such toys encourage them to consume toy qualities. As a result the child becomes a toy accessory guided by the toy instead of the other way round.

Our observations and studies showed big differences of playing with traditional and interactive toys. When children play with tech toys, the game is reduced to pushing buttons and observing the actions of the toys. "Program" embedded in an interactive toy changes the nature of the play: reduces the initiative and variety of play actions, speech activity of children and their interaction. So our presumption is that necessary condition for kid's play activity is toys "inactivity", i.e. the lack of technical equipment (Smirnova, 2011; Smirnova, Salmina, Abdulaeva, Filippova, \& Sheina, 2008).

But adults by making the task easier for children and confining their play to monotonous stereotype movements, limit their capacities for independent meaningful actions and therefore inhibit their development.

Tech toys have become increasingly popular. Parents consider them to be more modern and useful than the traditional "passive" toys. Tech toys, and electronic games present a new developmental situation and it is necessary to study the impact this kind of activities have on the development of young children. So, the task to evaluate the developmental qualities of particular toys arise.

\section{Psychological examination of toys}

The psychological examination of toys is realized in Play \& Toys centre of MSUPE. This examination is based on Vygotskian theory - on the possibility for toys to become a real psychological tool (Smirnova, 2011; Smirnova et al., 2008). Psychological and pedagogical evaluation of toys take into account not only their aesthetics properties, but the potential psychological effect on child's development is especially important. Such examination must base on impersonal, scientific criteria for assessing toys' potential impact on child's development.

Let's shortly describe the main aspects of psychological examination of toys. The examination includes three steps. 
The first one is the motivational basis of the play, which is corresponded with the attractiveness of toys for the child. It should make child to act and provides the motivation of play activities. Interests and tasks of the adult (toy as a mean of education) and a child (toy as a tool of play) are crossed in the toy. On the one hand the toy should encourage education and development, to be useful for kid's future, and on the other hand every toy should to be attractive and entertain the child, to bring him the pleasure of the moment. In order to stimulate meaningful children's toy activity a toy should serve the interests of the child, consistent with its needs, be attractive. The attractiveness of toys such as matching the interests and senses of a child is an important requirement for toys that actually encourages independence initiative activity. Only in this case, it makes child to act and provides the motivation of play activities.

The second and the main step is the evaluation of toy's developmental potential. The possibility of toy to become a developmental tool largely depends on the toy's qualities that may facilitate or interfere with their performing their basic function.

Suggestions of activity in toy may be more or less open. The toy should open up horizons for the child's creative and meaningful activity, it should offer a wide range of variants. Objects that presuppose useful yet stereotyped and monotonous actions can be used for exercises and training but not for playing. It is highly important for a developmental toy to be open for varied and actions.

We evaluate the development potential not of toy itself but of play actions with it. Toy as the object of children's play (or tools of activity) determine the character of the play, inspire the direction and the play, in other words, toy orients the child on certain actions. To perform its developmental function a toy should suggest adequate and culturally consistent guidelines for child's play action, that is orientate towards what should be done with it and how to encourage the child to realize the toy's potentials.

As it was noted earlier playing is a free and independent activity. The toy should open up horizons for the child's creative and meaningful activity, it should offer a wide range of variants. Objects that presuppose useful yet stereotyped and monotonous actions can be used for exercises and training but not for playing. It is highly important for a developmental toy to be open for varied and actions.

Developmental potential of toy depends on the character and variability of play action and its relation to the needs and potential of the age. For example, a doll as a person's substitution (partner in pretend play) is always reflects the experience of the child. That is why Barbie for a toddler is too complex: it carries too wide and not yet available for her social context, which will remain unclaimed. At the same time, this doll's image interferes the realization of the actions that the child can understand such as to rock to sleep, feed spoon, punishment for disobedience etc.

A good toy ought primarily to be open to the different actions and emotions of the child. Toy as the object of play orients the child on certain actions. To perform its developmental function a toy should suggest adequate and culturally consistent guidelines for child's play 
action, that is, orientate towards what should be done with it and how and to encourage the child to realize the toy's potentials. Suggestions for independent children's actions and their clearness for the child are two indispensable qualities of all developmental toys. They could direct rigid activity or allow child's initiative.

Contents of the play action (what kind of actions can be performed with the toy and for what type of play it can be used) determines the age (age range) in which the toy may have a maximum developmental effect. Play actions should not contradict each other. For example, there are some games are based on material for students (reading, account etc.), but the rules of the game focused on preschool children. As a result, these games are not interested neither small children ones nor students.

The third aspect of examination concern is the operational basis of play, providing the possibility of execution of the play action. Toys' operational possibilities contribute to the realization of the developmental potential. The playing material should correspond to practical paying activities because they are realized by the child independently. The purely physical descriptions such as size and weight may also either encourage or discourage the child. The feasibility of practical actions with a toy is also determined by several factors, the toy's durability and its high quality in the first place. These are not purely technical requirements: they are directly related to playing activities and ensure the possibility of playing with a toy. In case the toy corresponds to these criteria, it is noted by a special sign which draws to her attention of parents and teachers.

This examination doesn't forbid anything, doesn't limit the choice of adults, but draws attention of buyers to good toys. It is possible to hope that it can positively influence the choice of parents for really developing toys, and also to understand the relationship between the toys children play with and the abilities children can and do not can develop playing with certain type of toys and games.

\section{References}

Elkonin, D. B. (1978). Psychology of play. Moscow: Pedagogika.

Smirnova, E. O. (2011). Psychological and educational evaluation of toys in moscow center of play and toys. Psychological Science and Education(2), 5-10.

Smirnova, E. O., Salmina, N., Abdulaeva, Y., Filippova, I., \& Sheina, Y. (2008). Psychological and pedagogical principles of toy expert assessment. Social sciences, 39(3), 86-96.

Vygotsky, L. S. (1982). Collected works in 6 volumes. Vol. 2. Moscow: Pedagogika.

Vygotsky, L. S. (1984). Collected works in 6 volumes. Vol. 4. Moscow: Pedagogika.

Vygotsky, L. S. (2004). Igra i ee rol' v psikhicheskom razvitii rebenka. In Psikhologiya razvitiya rebenka (p. 200-234). Moscow: EKSMO.

Vygotsky, L. S. (2005). Appendix. From the notes of L. S. Vygotsky for lectures on the psychology of preschool children. Journal of Russian and East European Psychology, 43(2), 90-97. 